\title{
Evidência observacional das brisas do lago de Balbina (Amazonas) e seus efeitos sobre a concentração do ozônio.
}

\author{
Marcos Antonio Lima MOURA ${ }^{1}$, Franz X. MEIXNER ${ }^{2}$, Ivonne TREBS ${ }^{2}$, Roberto Fernando da Fonseca LYRA ${ }^{1}$, \\ Meinrat O. ANDREAE ${ }^{2}$, Manoel Ferreira do Nascimento FILHO ${ }^{1}$.
}

\section{RESUMO}

Mecanismos de vento local, tal como as brisas, influenciam o transporte e dispersão dos gases. Medidas da direção do vento e concentração de ozônio $\left(\mathrm{O}_{3}\right)$ à 10 metros de altura foram realizadas durante a execução do projeto LBA/CLAIRE2001 (Large Scale Biosphere-Atmosphere Experiment in Amazônia / Cooperative LBA Airbone Regional Experiment 2001), no período de 02 a 28.07.2001, nas dependências do Laboratório de Limnologia $\left(01^{\circ} 55^{\prime} \mathrm{S}, 59^{\circ} 28^{\prime} \mathrm{W}, 174 \mathrm{~m}\right)$ pertencente à Usina Hidrelétrica de Balbina, Amazonas. O lago artificial tem uma área de $2.360 \mathrm{~km}^{2}$, sendo suficientemente grande para estabelecer um regime de brisas. As brisas de lago e floresta apresentam-se de forma bem definidas, sendo que a brisa de lago fica melhor caracterizada no período mais quente do dia (10 às 14 horas), enquanto a brisa de floresta evidencia-se no período de 16 às 08 horas com o resfriamento radiativo mais intenso da floresta, o que acarreta um forte contraste térmico. Enquanto isso, a concentração média diária $\left(24\right.$ h) de $\mathrm{O}_{3}$ foi de 8,7 ppbv com média de 10,6 ppbv no período diurno e 3,5 ppbv no período noturno. Os resultados também indicaram que quando a brisa é de lago, mesmo a noturna, a concentração de $\mathrm{O}_{3}$ é muito maior do que correspondente a concentração referente a brisa de floresta.

\section{PALAVRAS-CHAVE}

Floresta Amazônica, Lago, Brisa, Ozônio

\section{Observational evidence of lake breezes at Balbina lake (Amazonas, Brazil) and their effect on ozone concentrations.}

\begin{abstract}
Local wind systems, such as sea or lake breezes, strongly affect the transport and dispersion of atmospheric trace gases. Based on its size and location, the artificial lake of Balbina in the Amazon - can be expected to give rise to a lake/forest breeze regime. During the period 2 to 28 July 2002, within the LBA/CLAIRE-2001 experiment, we have continually measured the ozone concentrations $\left(\mathrm{O}_{3}\right)$ and the wind directions close to the Balbina dam. We found that there is indeed a well established breeze system, with lake breezes prevailing during mid-day (10 to 14 LT) while forest breezes prevail from the afternoon to early morning (16 to $8 \mathrm{LT}$ ). During the latter period radioactive cooling in the forest creates a strong local thermal contrast. The average daily ozone concentration was 8.7 ppbv, with an average of 10.6 ppbv during the day, and 3.5 ppbv at night. When local winds came from the lake, even at night, ozone concentrations were greater compared to breezes coming from the forest.
\end{abstract}

KEY WORDS

Amazonian Forest, Lake, Breeze, Ozone

\section{INTRODUÇÃO}

$\mathrm{Na}$ atual conjuntura a abordagem do tema desmatamento da floresta amazônica exige uma visão estereoscópica da questão, principalmente quanto aos aspectos biogeoquímicos. Para tanto é preciso estabelecer critérios e inter-relações capazes de definir as modificações que estes desmatamentos proporcionam, já que essa região vem passando por modificações em sua cobertura vegetal com a derrubada e queimadas, causando impactos ambientais locais, em especial no tempo e no clima (Gielow et al., 2001)

Florestas tropicais são de considerável interesse científico porque são dinâmicas e estruturalmente diversificadas. A Amazônia Brasileira correspondente a 60\% do território

\footnotetext{
${ }^{1}$ Departamento de Meteorologia/ Universidade Federal de Alagoas -BR 104 - km 14 - Tabuleiro - Maceió - Alagoas - Brasil-57.072-970 - malm@fapeal.br rffl@ccen.ufal.br

${ }^{2}$ Max Planck Institute for Chemistry/Biogeochemistry Dept. - D-55020 - Mainz-Alemanha - meixner@mpch-mainz.mpg.de ; andreae@mpch-mainz.mpg.de
} 


\section{ACTA \\ AMAZONICA}

EVIDÊNCIA OBSERVACIONAL DAS BRISAS DO LAGO DE BALBINA (AMAZONAS) E SEUS EFEITOS SOBRE A CONCENTRAÇÃO DO OZÔNIO brasileiro e $40 \%$ das florestas remanescentes no mundo desempenham um papel vital na manutenção da biodiversidade, ciclo hidrológico e clima regional (Fearnside, 1999), além de ser uma das principais fontes de aquecimento da atmosfera terrestre graças a enorme quantidade de calor latente liberado na atmosfera pelas chuvas (Molion, 1976).

O ciclo diurno de aquecimento da superfície terrestre, devido à diferença na capacidade calorífica entre o solo (superfície) e o corpo d'água, pode produzir uma diferença de temperatura entre o solo e a superfície do lago, especialmente sob condições de céu claro. Isto resulta em uma correspondente diferença entre a temperatura do ar, que na ausência de um forte fluxo gradiente pode gerar uma circulação atmosférica localizada. Esse fenômeno tem sido observado e é usualmente descrito como uma brisa de lago (direção lago-floresta) durante o dia e brisa terrestre (direção terra-lago) a noite (Simpson, 1994). Oliveira e Fitzjarrald (1993) comprovaram a existência da brisa fluvial na Amazônia nos baixos níveis (até 1500-2000m), possuindo o sentido floresta/rio durante a noite e início da manhã, revertendo o sentido (rio/floresta) durante a tarde e início da noite. Naturalmente estes processos são mais intensos nas regióes em que a largura do rio é considerável.

Já o estudo de trocas de gases traços $\mathrm{NO}_{2}-\mathrm{NO}-\mathrm{O}_{3}$ (Dióxido Nítrico - Óxido Nítrico-Ozônio, respectivamente) em regiões amazônicas, que tem sido submetidas a modificação extrema em seus ecossistemas, é fundamental para o entendimento de como esses ambientes afetam a química global da troposfera. A associação com $\mathrm{NOx}$ no estudo do $\mathrm{O}_{3}$ melhora o entendimento sobre o ciclo do nitrogênio. Em associação com o NOx, o estudo das trocas superficiais de $\mathrm{O}_{3}$ tem implicações no clima e biologia regional (Fishman et al., 1979; Ramanathan et al., 1987).

A vasta região de ecossistemas tropicais tem uma profunda influencia nos padrões de concentração regional de gases críticos, tal como o óxido nitroso $\left(\mathrm{N}_{2} \mathrm{O}\right)$. Esses ecossistemas emitem também quantidades significativas de gases reativos, tais como o $\mathrm{NO}$ e os hidrocarbonetos não metanos (NMHC). Esses gases são críticos na determinação do poder oxidativo da atmosfera, afetando diretamente a produção e destruição de $\mathrm{O}_{3}$ (Crutzen, 1995). Estudos da variação do $\mathrm{O}_{3}$, sua produção e destruição fotoquímica na atmosfera tropical, são importantes no entendimento da capacidade de oxidação e ciclo atmosférico de alguns gases traços em baixas latitudes (De Serve et al., 1996). A alta intensidade de radiação ultravioleta (UV), combinada com alta umidade na atmosfera tropical, resultam em um aumento da quantidade de radical $\mathrm{OH}$ proveniente da fotólise do $\mathrm{O}_{3}$ (Crutzen et al., 1985). Ao mesmo tempo, florestas tropicais emitem grande quantidade de Hidrocarbonetos Não Metanos (NMHC) e CO, de atividade biogênica de larga escala e queima de biomassa que, por sua vez, pode ser oxidada para produzir $\mathrm{O}_{3}$ com grande eficiência (Kirchhoff \& Rasmussen, 1990).

$\mathrm{O}$ transporte e dispersão de gases são freqüentemente e extremamente afetados pelos sistemas de ventos locais, tais como as brisas. Então, este trabalho objetiva caracterizar o fenômeno da brisa no lago da Hidrelétrica de Balbina, Amazonas, e sua influência sobre a concentração do ozônio durante um mês da estação seca.

\section{MÉTODOS}

O clima atual da região amazônica é uma combinação de vários fatores, sendo que o mais importante é a disponibilidade de energia solar, através do balanço de energia. Quanto ao regime térmico, o clima é quente, com temperaturas médias anuais variando entre $24^{\circ}$ e $26^{\circ} \mathrm{C}$. A Região Norte possui uma homogeneidade espacial e sazonal da temperatura, o que não acontece em relação à pluviosidade. A região central amazônica possui uma precipitação média anual de aproximadamente $2500 \mathrm{~mm}$, embora tenham regiões (na fronteira entre Brasil e Colômbia e Venezuela) em que o total anual atinge $3500 \mathrm{~mm}$. A estação chuvosa da região amazônica muda progressivamente de janeiro-fevereiro-março, no sul da Amazônia, para fevereiromarço-abril, na parte central. Já a estação seca, ainda no centro, ocorre nos meses julho-agosto-setembro. Esta variação parece estar relacionada com a posição da Zona de Convergência InterTropical (ZCIT), segundo Fisch et al. (1996).

Durante o período de 02 a 27 de julho de 2001uma parte da campanha do experimento LBA/CLAIRE-2001 (Large Scale Biosphere-Atmosphere / Cooperative LBA Airbone Regional Experiment-2001) foi conduzida nas dependencias do laboratório de Limnologia ( $01^{\circ} 55^{\prime} \mathrm{S}, 59^{\circ}$ 28' W, $174 \mathrm{~m}$ ) pertencente à Usina Hidrelétrica de Balbina (Eletronorte) construída no Rio Uatumã no povoado de Balbina, município de Presidente Figueiredo, distante 155 $\mathrm{km}$ ao Norte de Manaus, Amazonas. O lago artificial da hidrelétrica tem uma área $2.360 \mathrm{~km}^{2}$ (Figueiredo \& Laraque, 1999). Segundo Miranda et al. (2003), apesar do reservatório ter sido cheio sem a remoção da cobertura vegetal densa (desmatamento só ocorreu nos arredores da represa), o que faz com que grandes áreas sejam ocupadas por troncos de árvores mortas, que emergem da superfície líquida e fornece substrato para fixar macrófitas. Com isso o sítio experimental caracteriza-se por dois aspectos: os setores de $60^{\circ}-280^{\circ}$ são constituídos de florestas intactas, enquanto no setor $280^{\circ}-60^{\circ}$ localiza-se a referida barragem, conforme pode ser visto na figura 01 .

Medições das variáveis meteorológicas e da concentração do $\mathrm{O}_{3}$ foram feitas a cada 10 s, com armazenamento das médias a cada minuto, gerando um total de $n=20.484$ / variável. As medidas foram realizadas em uma torre de 10 $\mathrm{m}$, onde utilizou-se os seguintes instrumentos: direção e velocidade do vento (Vector Instruments, Reino Unido), temperatura e umidade do ar (MP 340, Rotronic, Suiça), radiação global (SP Lite, Kipp \& Zonen, Holanda) e precipitação (Campbell Scientific, Reino Unido). Já o $\mathrm{O}_{3}$ foi medido com um analisador de absorção de radiação Ultravioleta (Thermo Instruments TE 49C, EUA), cuja coleta foi feita com uma mangueira TEFLON azul de 1/4" (6.325mm) e 36 metros de comprimento, com a extremidade aberta 


\section{ACTA AMAZONICA}

EVIDÊNCIA OBSERVACIONAL DAS BRISAS DO LAGO DE BALBINA (AMAZONAS) E SEUS EFEITOS SOBRE A CONCENTRAÇÃO DO OZÔNIO protegida por uma malha fina contra pequenos insetos fixada a 10 metros de altura no mastro da torre meteorológica, sendo a outra extremidade conectada a uma bomba de vácuo (ESD Edwards High Vacuum International, Reino Unido). Na saída da bomba foi colocada uma distribuição através de conexões de mangueira TEFLON do mesmo diâmetro para o analisador. Os dados coletados pelo analisador foram transferidos digitalmente via interfaces seriais. Um programa LabView (National Instruments, EUA), em um Laptop, em combinação com um outro instrumento de aquisição de dados (DAQPad-1200, National Instruments, EUA), foi usado para controlar o sistema de gases, armazenamento e processamento dos dados em tempo real.

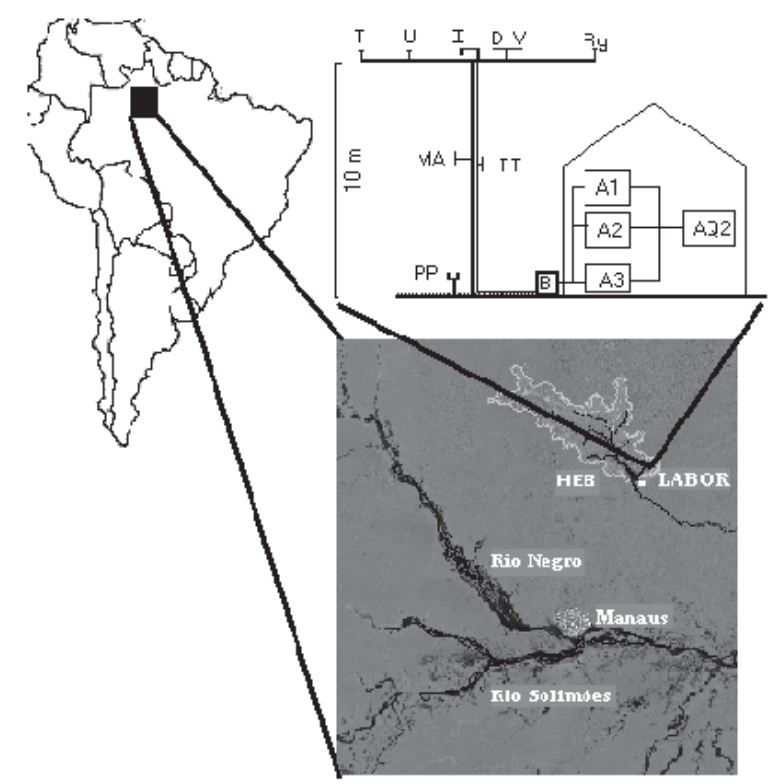

Figura 1 - Localização geográfica do Laboratório de Limnologia (LABOR) da Hidrelétrica de Balbina (HEB). No detalhe, esquema dos instrumentos de medição: Temperatura e Umidade do ar (T,U), Inlet dos gases (I), Direção e Velocidade do ar (D,V), Radiação global (Rg), Precipitação (PP), Mastro (MA), Tubo Teflon (TT), Bomba (B), Analisadores dos Gases (A1, A2 e A3) e Aquisição de Dados (AQ2).Fonte Imagem Satélite: JERS-1 Global Rain Forest Mapping Project South América, 1995-1996, V. AM-1.

\section{RESULTADOS E DISCUSSÃO}

O principal fator que determina o modelo de circulação do ar sobre a região de um lago é o efeito térmico entre as superfícies líquida e terrestre que por sua vez gera uma diferença de pressão e, conseqüentemente conduz um fluxo líquido de ar em uma ou outra direção. Segundo Jazcilevich et al. (2002), esse campo de vento apresenta-se de forma radial, onde a sua intensidade é diretamente proporcional à magnitude do gradiente horizontal de temperatura e da altura da perturbação da temperatura na atmosfera, cujo conceito fundamental foi mostrado matematicamente por Pielke \& Segal (1986).

Observa-se na figura 2 a que o vento tem as direções Norte e Sul como predominantes numa clara caracterização do fenômeno das brisas. Quando plotamos somente os dados noturnos (18 às 06 horas) (figura 2 b) o vento deslocase quase que exclusivamente na direção floresta-rio, devido ao contraste térmico. Estendendo um pouco mais este período, nota-se na figura $2 \mathrm{c}$ que este contraste térmico inicia-se aproximadamente às 16 horas prolongando-se até às 08 horas, uma vez que a direção predominante do vento é de sul (floresta). A brisa terrestre forma-se próximo ao pôr do Sol, quando começa o resfriamento radiativo da superfície, visto que a superfície terrestre resfria-se mais rapidamente do que a superfície do lago; então o ar sobre a superfície terrestre torna-se mais frio do que o ar sobre a superfície líquida e inicia-se o contraste entre ambos. Talvez pelo fato de que nessa época do ano, as precipitações são primordialmente de características convectivas, ocorrendo com mais freqüência nos horários de maior aquecimento, que é no período vespertino, segundo Ferreira da Costa et al. (2000), este resfriamento seja intensificado antes do anoitecer. Observações radiométricas feitas por avião durante o experimento ABLE revelam um gradiente térmico entre o rio Amazonas e a floresta de $-3{ }^{\circ} \mathrm{C}$ durante o dia e 6 ${ }^{\circ} \mathrm{C}$ à noite (Oliveira e Fitzjarrald, 1993). Entretanto, o resfriamento radiativo também estabiliza a camada limite noturna, tão que a circulação da brisa terrestre é inibida verticalmente. Velocidades máximas do vento dentro da circulação são significativamente menores do que em brisa de lago devido a essa restrição (Pielke \& Segal, 1986).

Se analisarmos o período diurno (06 às 18 horas) (figura 2d) não é possível distinguir claramente a brisa de lago (direção lago-floresta) (predominância de vento de Norte). Ou seja, a distribuição da freqüência de direção do vento mostra-se ainda com predominância tanto de Norte como de Sul. Isso acontece pelo fato do sistema terra/atmosfera necessitar de um período para se adaptar a nova situação de contraste térmico, que por sua vez dependerá do aquecimento proporcionado pela chegada da radiação solar, como também pode possivelmente estar sendo influenciado pelos desmatamentos ao redor do lago. Quando se toma por base o período mais quente do dia (10 às 14 horas) (figura 2e), a brisa do lago fica melhor caracterizada, mas ainda assim indicando algum vento do quadrante Sul.

Geralmente para que a direção do vento originado da brisa não seja bem evidenciada é necessário que haja a influência ou de células de processos convectivos que se formam com o aquecimento da atmosfera ou de algum sistema de grande escala. Tanto que Ryzmar \& Touma (1981) afirmaram que a circulação da brisa do lago normalmente dissipa-se quando variações na temperatura do ar sobre a superfície líquida ou terrestre eliminam o gradiente horizontal de pressão. Diante disso, depois de uma análise detalhada dos dados diários excluímos oito dos 26 dias de observações $(04,05,08,19,21,22,25$ e 27.07). Como 


\section{ACTA \\ AMAZONICA}

EVIDÊNCIA OBSERVACIONAL DAS BRISAS DO LAGO DE BALBINA (AMAZONAS) E SEUS EFEITOS SOBRE A CONCENTRAÇÃO DO OZÔNIO (a)

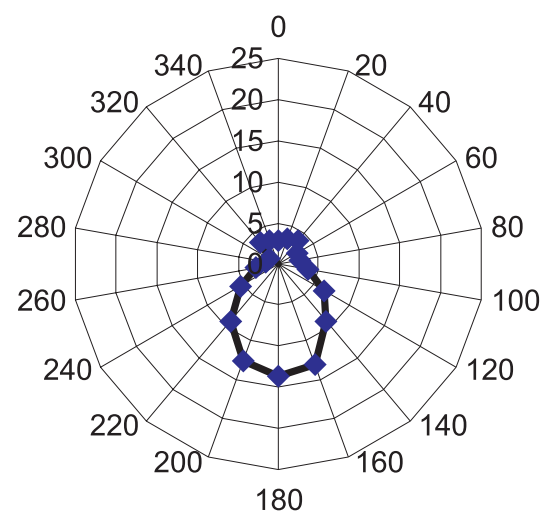

(e)

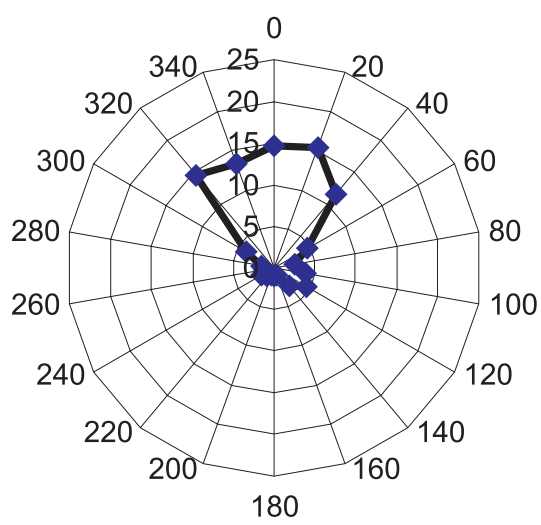

(c)

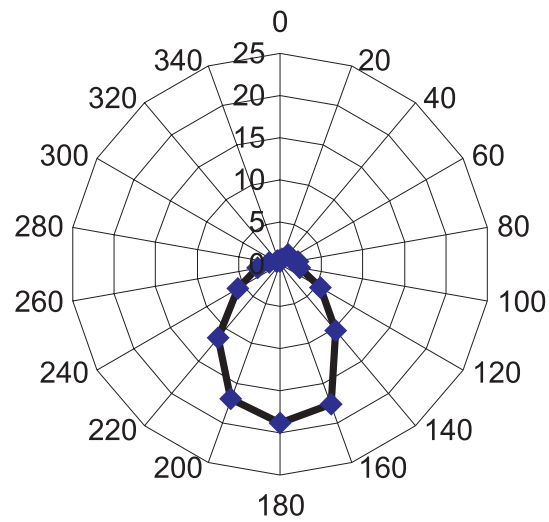

(b)

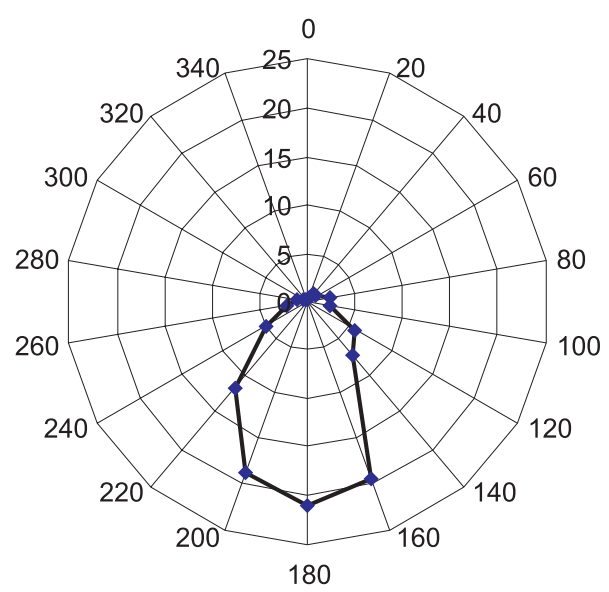

(f)

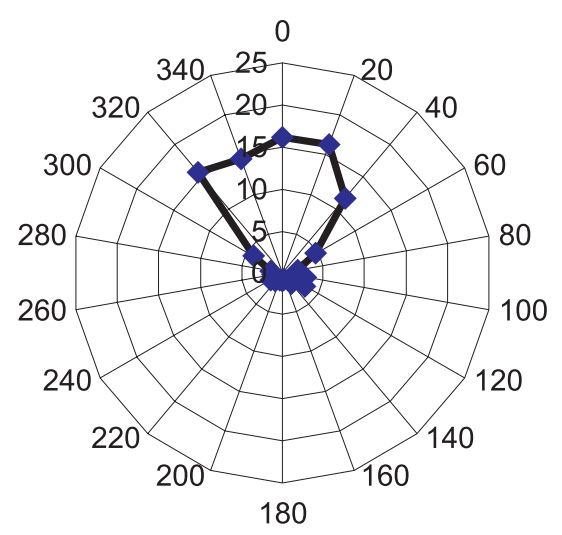

(d)

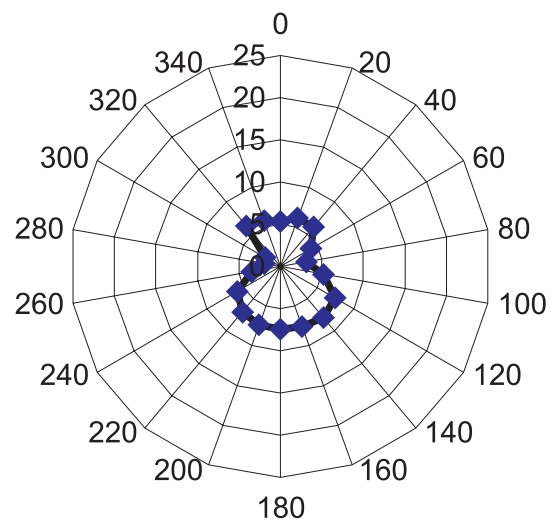

Figura 2 - Distribuição da freqüência (\%) da direção do vento (graus): (a) 0 às 24 horas, (b) 18 às 06 horas, (c) 16 às 08 horas, (d) 06 às 18 horas, (e) 10 às 14 horas e (f) 10 às 14 horas com a exclusão dos dias 04, 05, 08, 19, 21, 22, 25 e 27.07.2001. 


\section{ACTA AMAZONICA}

EVIDÊNCIA OBSERVACIONAL DAS BRISAS DO LAGO DE BALBINA (AMAZONAS) E SEUS EFEITOS SOBRE A CONCENTRAÇÃO DO OZÔNIO resultado a figura $2 \mathrm{f}$ apresenta alta freqüência da direção do vento no sentido lago-floresta (brisa de lago), deixando explicito que a circulação local do ar sofreu provavelmente alguma influência de grande escala nos dias eliminados

Segundo Reitebuch et al. (2000) as medidas do curso diário da concentração do $\mathrm{O}_{3}$ mostram os resultados da interação dos diferentes mecanismos, onde reações químicas, principalmente fotólise do $\mathrm{NO}_{2}$, induzem concentrações diárias máximas da quantidade de $\mathrm{O}_{3}$, química do ar induz a destruições do $\mathrm{O}_{3}$ (mais efetivamente por titração com o NO à noite), deposição remove $\mathrm{O}_{3}$ das camadas atmosféricas próximas à superfície, ventos médios resultam em considerável transporte horizontal e a mistura turbulenta acarreta troca vertical. O curso médio diário da concentração do $\mathrm{O}_{3}$ (figura 3) apresenta-se decrescente até próximo a zero durante a noite e valores máximos alcançados no período vespertino (20,3 ppbv às 14 horas). Nesses ambientes a concentração do $\mathrm{O}_{3}$ tende a seguir a intensidade da radiação solar, resultando em alta concentração do $\mathrm{O}_{3}$ durante o período diurno. Nesses ciclos, o aumento do nível de concentração do ozônio durante o período diurno é atribuído ao efeito combinado de produção fotoquímica do ozônio na camada de mistura e o transporte advindo das camadas superiores, que é favorecida ao meio-dia pela atividade convectiva e, conseqüentes movimentos subsidentes associados, sendo ambos mecanismos ativados pela radiação solar. À noite, o resfriamento noturno por radiação à superfície proporciona uma camada estável termodinamicamente, cuja inversão de temperatura leva a destruição local do $\mathrm{O}_{3}$ pelas bem conhecidas reações entre $\mathrm{O}_{3}$ e NO. A baixa concentração do $\mathrm{O}_{3}$ noturno e o mínimo matinal podem ser compreendidos principalmente como um resultado da deposição seca noturna e reações químicas (com o NO) à superfície, especialmente se a mistura de cima é limitada por fortes gradientes verticais de densidade (Wesely \& Hicks, 2000). Uma outra possibilidade seria a variação na emissão pela superfície de NO, que segundo Meixner (1994), através de uma variedade de processos bioquímicos (denitrificação e nitrificação), numerosos grupos de microorganismos no solo contribuem para a produção e consumo de NO.

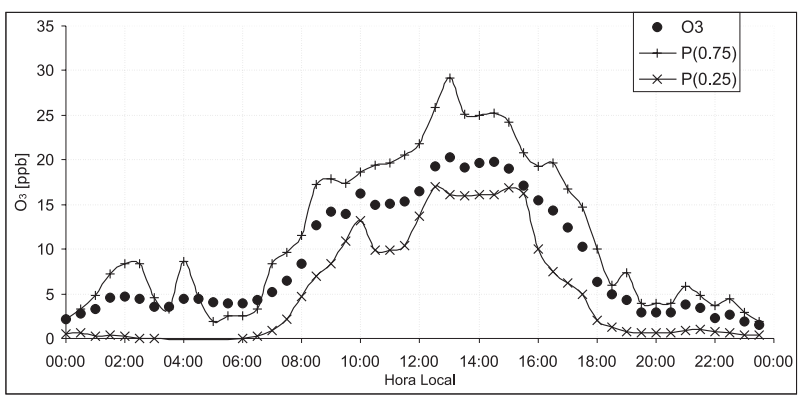

Figura 3 - Ciclo diário médio da concentração do Ozônio $\left(\mathrm{O}_{3}\right)$ (ppbv) com os respectivos percentis 75 e 25 , no período de 02 a 27 de julho de 2001.
Segundo Cheng (2002) a concentração do $\mathrm{O}_{3}$ em um determinado local depende significativamente das taxas de emissões advectadas e mistura vertical, como também da variação local do campo de vento. Então, quando se associa a concentração do $\mathrm{O}_{3}$ com a brisa do lago, principalmente no período de 10 às 14 horas (figura 04), pode-se notar que a concentração do $\mathrm{O}_{3}$ é sempre alta quando o vento é proveniente do lago, com média de 18,6 ppbv, enquanto a média é de 5,2 ppbv quando o vento vem da floresta. Segundo Wesely \& Hicks (2000) as superfícies líquidas (lagos) são conhecidas por reduzidas taxas de deposição de $\mathrm{O}_{3}$ em comparação com o observado em superfícies terrestres, podendo ser menor do que $0,01 \mathrm{~cm} . \mathrm{s}^{-1}$. Isso pode ser exemplificado na figura 05 , referente ao dia 17.07.01, no qual o vento, mesmo no período noturno, era proveniente do lago por algum motivo, mas mesmo assim a concentração de $\mathrm{O}_{3}$ se mantém relativamente alta devido à baixa velocidade de deposição. Para Lyons \& Cole (1976) outros fatores que envolvem uma acentuada concentração do $\mathrm{O}_{3}$ peculiar a brisa do lago são: suprimento abundante de hidrocarbonos reativos e óxido de nitrogênio, forte insolação, temperatura do ar relativamente alta, velocidade do vento pequena e altura de mistura limitada.

Examinando a concentração de $\mathrm{O}_{3}$ no período das 18 às $06 \mathrm{~h}$ (Figura 6) quando ocorre principalmente brisa de floresta (figura 2c), observa-se que a concentração do $\mathrm{O}_{3}$ é muito mais alta nos poucos momentos em que o vento soprou do lago (quadrante norte). Segundo Zaveri et al. (1995) depois do pôr do Sol a concentração de $\mathrm{O}_{3}$ na camada superficial decresce rapidamente pelo mesmo ser depositado na superfície ou exaurido quimicamente da atmosfera, o que

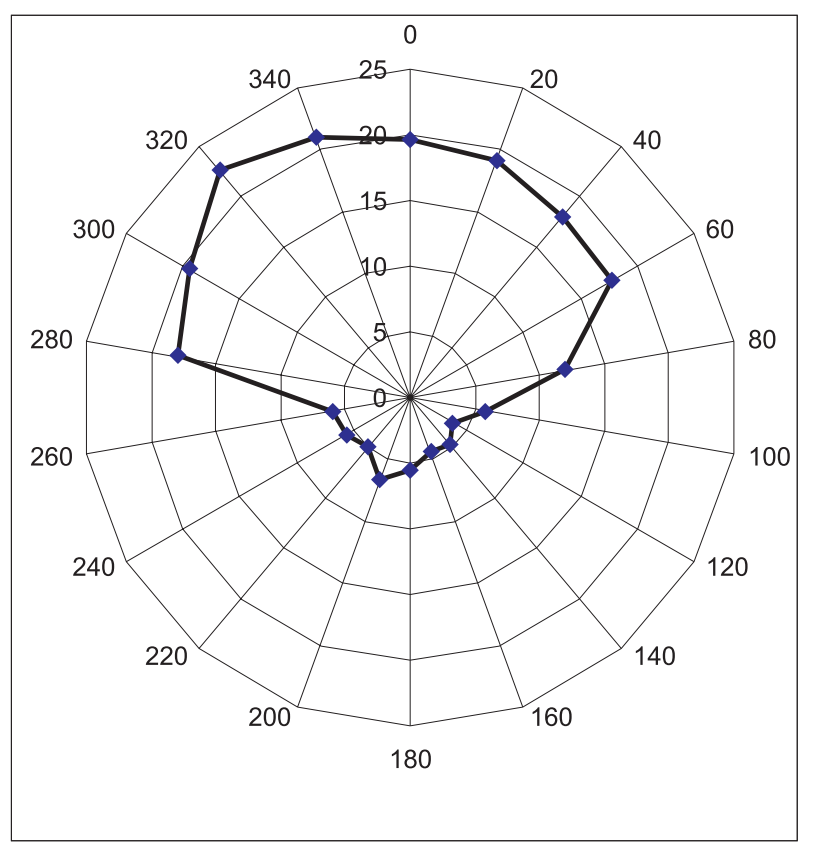

Figura 4 - Distribuição da concentração média do Ozônio (ppbv) em função da direção do vento (graus) no horário das 10 às 14 horas. 


\section{ACTA AMAZONICA}

EVIDÊNCIA OBSERVACIONAL DAS BRISAS DO LAGO DE BALBINA (AMAZONAS) E SEUS EFEITOS SOBRE A CONCENTRAÇÃO DO OZÔNIO pode ser exemplificado pela figura 07 , que é referente ao dia 20.07.01, representante característico da brisa de floresta, quando se observa que a concentração do $\mathrm{O}_{3}$ é muito baixa (próximo a zero), pelos motivos anteriormente descritos.

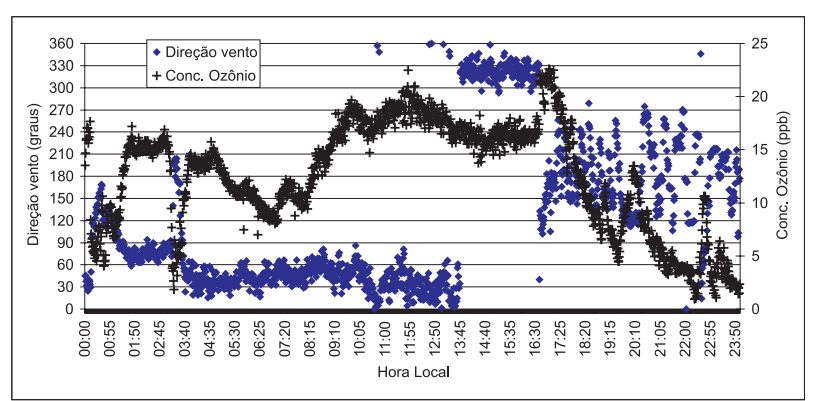

Figura 5 - Detalhe da concentração medida do ozônio (ppbv) e da direção do vento (graus) medidas a cada minuto no dia 17.07.2001

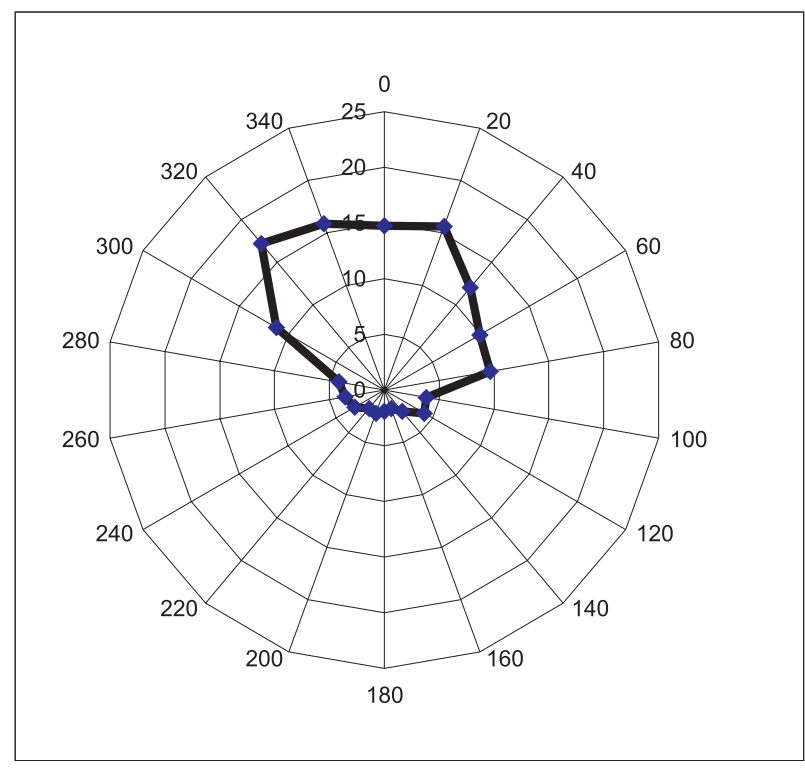

Figura 6 - Distribuição da concentração média do Ozônio (ppbv) em função da direção do vento (graus) no horário das 18 às 06 horas (Considerar Figura 2c para correspondente freqüência da distribuição do vento).

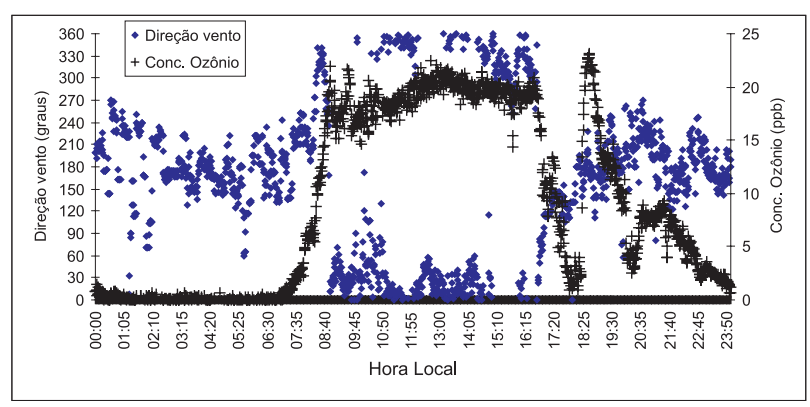

Figura 7 - Detalhe da concentração medida do ozônio (ppbv) e da direção do vento (graus) medidas a cada minuto no dia 20.07.2001.

\section{CONCLUSÕES}

Através das análises dos dados obtidos foi possível a constatar a existência das brisas de lago e floresta que são oriundas do contraste térmico entre as referidas superfícies. Quando não se tem na região influencia dos sistemas de grande escala foi possível determinar nitidamente a brisa do lago (direção do vento lago-floresta) no horário mais quente do dia (10 às 14 horas), enquanto a brisa de floresta evidencia-se logo após o resfriamento radiativo da superfície, o que pode ocorrer a partir das 16 horas prolongando-se até às 08 horas.

Uma importante característica observada foi que a brisa do lago exerce expressiva influencia sobre a concentração do ozônio, pois a concentração do mesmo foi maior, independentemente do horário, quando o vento sopra do lago. Isso está relacionado a pequena taxa de velocidade de deposição sobre a superfície líquida. Normalmente a concentração máxima do ozônio ocorre na parte vespertina, mas a média diária foi de 8,7 ppbv, sendo que a média diurna foi 10,6 ppbv e a noturna de 3,5 ppbv.

\section{AGRADECIMENTOS}

Os autores desejam deixar aqui registrado agradecimento especial ao Prof. Dr. Paulo Artaxo, do Instituto de Física/USP e Coordenador Brasileiro deste experimento e ao Coordenador Geral do LBA Dr. Carlos A. Nobre e colaboradores pela possibilidade de realização desta campanha, como também a toda equipe de pesquisadores da USP, IPEN, UFBA, UFAL, MPI e outras instituições que participaram dos trabalhos de campo. Também somos gratos a direção da Usina Hidrelétrica de Balbina e ao Laboratório de Limnologia da Hidrelétrica de Balbina por todo o apoio oferecido quando da realização da campanha experimental, e ao Dr. Joern von Jouanne do MPI Chemie, Mainz, pelo suporte logístico durante a campanha e pelas valiosas sugestões/discussões para elaboração deste trabalho. O primeiro autor (M.A.L.M ) agradece ao MPI Chemie, pelo apoio logístico e financeiro durante a campanha.

\section{BIBLIOGRAFIA CITADA}

Cheng, W. L. 2002. Ozone distribution in coastal central Taiwan under sea-breeze conditions. Atm. Environment, 36(21):3445-3459

Crutzen, P.J. 1995. Overview of tropospheric chemistry: Developments during the past quarter century and a look ahead. Faraday Discuss., 100: 1-21

Crutzen, P.J., Delany, A.C., Greenberg, J. et al. 1985. Tropospheric chemical composition measurements in Brazil during the dry season. J. Atmosph. Chemistry, 2: 233.256

De Serve, C., Rondon, A. and Oyola, P. 1996. Photochemical studies in the savanna boundary layer during wet season. Atm. Environ., 30: 1419.1427. 


\section{ACTA AMAZONICA}

EVIDÊNCIA OBSERVACIONAL DAS BRISAS DO LAGO DE BALBINA (AMAZONAS) E SEUS EFEITOS SOBRE A CONCENTRAÇÃO DO OZÔNIO
Fearnside, P. M. 1999. Biodiversity as an environmental service in Brazil's Amazonian forests: risks, value and conservation. Environmental Conservation, 26:305-321

Ferreira da Costa, R.; Pereira, A . R.; Fisch, G. et al. 1999. A mitigação do $\mathrm{CO}_{2}$ atmosférico na Amazônia brasileira central durante um período seco. Rev. Bras. Agrometeorol., 8:275-281

Figueiredo, M. D. M.; Laraque, A. Balbina: 10 anos depois. In: Manaus'99 -bydrological and geochemical processes in large scale riverbasins: extended abstracts. Brasília: HIBAM, 1999. 1 CD-ROM.

Fisch, G., Marengo, J. A ., Nobre, C. A . 1996. Clima da Amazônia. Climanálise Especial, Edição Comemorativa de 10 anos, 24-41

Fischman, J., Ramanathan, V., Crutzen, P. J. et al. 1979. Tropospheric ozone and climate. Nature, 282: 818-820

Gielow, R. ; Carvalho Jr., J. A ., Alvarado, E. et al. 2001. Evolução do albedo, saldo de radiação e fluxo de calor no solo após derrubada florestal seguida de queimada e rebrota na região de Alta Floresta, Mato Grosso. Anais XII Cong. Bras. Agromet., Fortaleza - 2001, II:859

Jazcilevich, A. D., García, A . R. ; Ruíz-Suárez, L. G. 2002. A modeling study of air pollution modulation through land-use change in the Valley of México. Atm. Environment, 36(14):2297-2307

Kirchhoff, V.W.J.H., Rasmussen, R.A. 1990. Time variations of CO and $\mathrm{O}_{3}$ concentrations in a region subject to biomass burning. J. Geophy. Res., 95: 7521.7532

Lyons, W.A., H.S. Cole. 1973. Fumigation and Plume Trapping on the Shores of Lake Michigan during Stable Onshore Flow. J. Appl. Meteorol., 12:494-510

Meixner, F. 1994. Surface exchange of odd nitrogen oxides. Nova Acta Leopoldina, NF70(288):299-348.

Miranda, F. P., Fonseca, L. E. N., Beisl, C. H. et al. 2003. Seasonal mapping of flooding extent in the vicinity of the balbina dam (central amazonia) using radarsat-1 and jers-1 sar data. Disponível em http://www.space.gc.ca/csa_sectors/ earth_environment /radarsat/research/adro1/adrocd/ger_97/ papers/037/37.pdf > . Acesso em 22.04.2003.
Molion, L. C. B. 1976. A climatology study of the energy and moisture of the Amazonas basin with considerations to the deforestation effect. Instituto Nacional de Pesquisas Espaciais - INPE, São José dos Campos, São Paulo, 140p.

Oliveira, A.P., Fitzjarrald, D.R. 1993. The Amazon river breeze and the local boundary layer: I - Observations. Boundary Layer Meteorol., 63(1-2): 141 - 162

Pielke, R.A., Segal, M. 1986. Mesoscale Circulations Forced by Differential Terrain Heating. In Mesoscale Meteorology and Forecasting (P.S. Ray, Ed.), Amer. Met. Soc., p.516-548.

Ramanathan, V., Callis, L., Cess, R. et al. 1987. Climate Chemical Interactions and Effects of Changing Atmospheric Trace Gases. Reviews in Geophysics, 25:1441-1482

Reitebuch, O. , Strassburger, A ., Emeis, S. et al. 2000. Nocturnal secondary ozone concentration maxima analysed by sodar observations and surface measurements. Atm. Environment, 34: 4315-4329

Ryznar, E. , Touma, J. S. 1981. Characteristics of True Lake Breezes along the Eastern Shore of Lake Michigan. Atm. Environment, 15:1201-1205

Simpson, J. E. 1994. Sea breeze and local wind. Cambridge University Press, Cambridge. 234p.

Wesely, M. L.; Hicks, B. B. 2000. A review of the current status of knowledge on dry deposition. Atm. Environment, 34:2261 2282.

Zaveri, R.A., Saylor, R.D., Peters, L.K. et al. 1995. A model investigation of summertime diurnal ozone behaviour in rural mountainous locations. Atm. Environment, 29:1043-1065

\author{
RECEBIDO EM: 18/12/2002 \\ ACEITO EM: 19/11/2003
}


